\title{
TLR9 Agonist EMD 1201081
}

National Cancer Institute

\section{Source}

National Cancer Institute. TLR9 Agonist EMD 1201081. NCI Thesaurus. Code C90533.

A synthetic olig onucleotide containing phosphorothioate oligodeoxynucleotide with potential immunopotentiating activity. TLR9 agonist EMD 1201081 binds to and activates the intracellular Toll-like receptor (TLR) 9 in monocytes/macrophages, plasmacytoid dendritic cells (DCs) and B cells, initiating immune signaling pathways, activating B cells and inducing T-helper cell cytokine production. TLR9 is a member of the TLR family, which plays a fundamental role in pathogen recognition and activation of innate immunity. 